\title{
Invasive management of renal cell carcinoma in von Hippel-Lindau disease
}

\author{
Diego M. Carrion ${ }^{1}$ Estefanía Linares-Espinós ${ }^{1,2}$, Emilio Ríos González ${ }^{1,2}$, Alfredo Aguilera Bazán ${ }^{1,2}$, \\ Mario Alvarez-Maestro ${ }^{1,2}$, Luis Martinez-Pineiro ${ }^{1,2}$ \\ ${ }^{1}$ Department of Urology, La Paz University Hospital, Madrid, Spain Autonomous University of Madrid, Madrid, Spain \\ ${ }^{2}$ La Paz University Hospital, Institute for Health Research (IdiPAZ), Madrid, Spain
}

Citation: Carrion DM, Linares-Espinós E, Ríos González E, Aguilera Bazán A, Alvarez-Maestro M, Martinez-Pineiro L. Invasive management of renal cell carcinoma in von Hippel-Lindau disease. Cent European J Urol. 2020; 73: 167-172.

Article history

Submitted: Jan. 5, 2020

Accepted: April 29, 2020

Published online: May 20, 2020

Corresponding author Estefanía Linares-Espinós La Paz University Hospital Department of Urology Paseo De La Castellana 261 28046 Madrid, Spain estefania.linares@salud. madrid.org
Introduction Patients affected by von Hippel-Lindau (VHL) disease experience an increased risk for bilateral, synchronous, and metachronous renal cell carcinoma (RCC). Oncologic and functional outcomes are the main goals in the management of renal masses. We present our protocol for patients with $\mathrm{VHL}$ disease-associated RCC alongside functional and oncologic results observed in our series. Material and methods We performed a retrospective analysis of our clinical database of patients with VHL disease-associated RCC referred to our department between June 2005 and December 2017. We offer surveillance for lesions $<2 \mathrm{~cm}$ and active management with radiofrequency ablation (RFA) for lesions 2-3 cm, and nephron-sparing surgery (NSS), RFA or embolization techniques for lesions $>3 \mathrm{~cm}$ or growth rate $>1 \mathrm{~cm} /$ year.

Results Our series comprises 14 patients, of whom 13 had undergone at least one invasive procedure for RCC, mean age at first intervention was 27 years (range 18-60). Overall, 30 interventions were performed in 21 kidneys: four radical nephrectomies, 13 RFAs, 12 NSSs, and one embolization. During follow-up (median time: 41 months, range: 6-149), eight patients (57\%) presented with new lesions that required treatment, with a mean time between treatments of $32 \pm 18.5$ months. No metastatic progression or need for dialysis was recorded; the success rate for RFA was $85 \%$.

Conclusions Management of VHL kidney disease by NSS is the standard of care with a cut-off at $3 \mathrm{~cm}$, ablative procedures should be offered to lesions ranging $2-3 \mathrm{~cm}$ in size. Follow-up should be done strictly in referral centers that can provide all treatment options to renal function and control oncologic progression.

Key Words: von Hippel-Lindau disease « radiofrequency ablation « nephron-sparing surgery () renal cell carcinoma

\section{INTRODUCTION}

Von Hippel-Lindau (VHL) disease is the most common hereditary renal cell carcinoma (RCC) cancer syndrome, presenting in 1 in 36,000 live births [1]. It is an autosomal dominant, highly penetrant inherited disorder caused by germline mutations in the VHL gene. VHL patients are at high risk of early and multiple clear cell RCC; approximately two-thirds will present multiple renal cysts and RCC during their lifetimes [1-4]. Extrarenal manifestations in- clude retinal angiomas, central nervous system hemangioblastomas, pheochromocytomas, pancreatic cystic lesions, neuroendocrine tumors, and cystadenomas of the epidermis, broad ligament and endolymphatic sac $[1,2,5]$.

RCCs in VHL patients are characterized by their multiplicity, bilaterality, and predominantly clear cell histology. They present with an age-dependent frequency, ranging from $25 \%$ up to $70 \%$, with a mean age at diagnosis of 40 years of age $[1,2]$. RCCs are the leading cause of death in patients with VHL, and 
median overall survival in these patients is around 50 years $[1,2]$. The most important risk factors for decreased life expectancy in VHL patients are the high prevalence of RCC and their high recurrence rate $[1,2,5]$.

Treatment decisions for RCCs in VHL depend on both the tumor size and growth kinetics of each lesion, as these parameters determine the risk of metastatic disease [6]. Nephron-sparing surgery (NSS) is currently the standard therapy for VHLassociated RCC and should be performed whenever technically feasible, mainly for lesions measuring $\geq 3 \mathrm{~cm}$ [7]. Percutaneous approaches for ablative techniques such as cryoablation, radiofrequency ablation (RFA), and microwave ablation (MWA) should be considered for tumors measuring $2-3 \mathrm{~cm}$ in diameter distant from vessels or bowel structures [8]. Considering that these patients will have a large number of microscopic RCCs and abundant cysts, the balance between the number of surgeries for oncologic control and renal function preservation remains vital in the management of VHL kidney disease. We herein report our protocol for the management of VHL disease associated RCC, and our cohort of patients managed with invasive procedures.

\section{MATERIAL AND METHODS}

We performed a retrospective analysis of a prospectively collected database of patients with VHL disease treated for renal masses at our institution between June 2005 and December 2017. Our hospital is a referral center for the management of RCC in VHL disease with minimally invasive approaches, endorsed by the Spanish Alliance for Families with VHL disease.

Patients were initially seen in the urology outpatient clinic and a comprehensive consultation was provided covering the various treatment options available according to our protocols. We offer standardized management, with active surveillance for lesions $<2 \mathrm{~cm}$, which consists of urologic evaluation and imaging every 3 to 6 months. Treatment is offered for lesions $\geq 2 \mathrm{~cm}$ or those with a growth rate of $\geq 1 \mathrm{~cm} /$ year. NSS (open or laparoscopic) is the preferred treatment modality for lesions $\geq 3 \mathrm{~cm}$. RFA or MWA (percutaneous or laparoscopic) or percutaneous selective embolization (SE) are the preferred treatments for lesions measuring between 2 to $3 \mathrm{~cm}$. Percutaneous ablative techniques (RFA and MWA) are not proposed for lesions that cannot be easily reached by the probe (anterior lesions), or located in close contact with adjacent structures (major vessels or intraabdominal organs). The interventional radiologist would then see patients who were advised and accepted a percutaneous RFA or SE in their outpatient clinic. Both the urologist and interventional radiologist provided an in-depth discussion of the pros and cons of each treatment modality, considering the size and location of the tumors selected for treatment. Controversial lesions are discussed at an oncologic multi-disciplinary meeting involving the interventional radiology and urology departments, which are held every 2 to 4 weeks. Follow-up after treatment includes magnetic resonance imaging (MRI) or computed tomography (CT) imaging of the abdomen at three months after surgery. If treatment is considered successful, an MRI is performed every six months thereafter.

Variables and patient data were recorded in our clinical VHL database. Patient demographics included: age, gender, confirmation of diagnosis with a genetic study, relatives affected, organs affected by VHL, Charlson comorbidity index, and renal status [serum creatinine and modification of diet in renal disease estimated glomerular filtration rate (eGFR)]. Therapeutic procedures recorded included: radical nephrectomy (RN), NSS, RFA, and SE. For each procedure, we recorded preoperative imaging characteristics, baseline renal function status, procedure outcomes, and results (number, size, and anatomopathological diagnosis including Fuhrman grade) and complications, according to the Clavien-Dindo classification. At the last follow-up visit, we recorded imaging results, oncologic, and renal function status. Time to disease progression was estimated as the time between procedures in every patient. Statistical analysis was performed using SPSS Statistics (V20; IBM Corp. Armonk, NY, USA).

\section{RESULTS}

From June 2005 to December 2017, 14 patients were referred to our VHL-RCC unit and consequently enrolled in our database. Three patients $(22 \%)$ were women, and $11(78 \%)$ men, the median age at diagnosis was 28 years old (range 18-60), and median age at the time of first intervention was 27 years (range 18-60), all of them having extrarenal manifestations. Demographic and perioperative data are summarized in Table 1. Thirteen patients underwent one or more procedures performed for RCC at our center, and one remains treatment naïve on active surveillance. Median follow-up in our series was 41 months (range 6-149).

Thirty procedures were performed overall in 21 kidneys, most commonly performed procedures were: 13 RFAs and 12 NSSs (four open and eight laparoscopic), followed by four laparoscopic RNs and one SE. Before being referred to our department, four 
Table 1. Demographic and perioperative data $(n=14)$

\begin{tabular}{|c|c|}
\hline Median age at diagnosis, years (range) & $27(18-60)$ \\
\hline Male / female, n (\%) & $3(22) / 11(78)$ \\
\hline Genetic study, n (\%) & $7(50)$ \\
\hline First-grade relative affected, $\mathrm{n}(\%)$ & $9(64)$ \\
\hline Extrarenal manifestations, $\mathrm{n}(\%)$ & $14(100)$ \\
\hline Cerebellar hemangioblastoma, n (\%) & $11(79)$ \\
\hline Pancreatic cysts, n (\%) & $9(64)$ \\
\hline Retinal angioma, n (\%) & $6(43)$ \\
\hline Pheochromocytoma, n (\%) & $2(14)$ \\
\hline Kidney solid lesions: unilateral / bilateral, n (\%) & $5(36) / 9(64)$ \\
\hline Benign kidney lesions (Bosniak I), n (\%) & $11(78)$ \\
\hline Median BMI, kg/m² (IQR) & $23(18-28)$ \\
\hline Median Charlson score (Range) & $2(0-4)$ \\
\hline $\begin{array}{l}\text { Patients that had only one intervention for kidney } \\
\text { tumors (\%) }\end{array}$ & $5(36)$ \\
\hline $\begin{array}{l}\text { Patients with multiple interventions for kidney } \\
\text { tumors (\%) }\end{array}$ & $8(57)$ \\
\hline Treatment naïve patients (\%) & $1(7)$ \\
\hline \multicolumn{2}{|l|}{ Mean serum creatinine, mg/dl ( $\pm S D$ ) } \\
\hline Basal & $0.8( \pm 0,2)$ \\
\hline At last visit & $1.0( \pm 0.7)$ \\
\hline \multicolumn{2}{|l|}{ Mean eGFR, (CKD-EPI) ml/min/1.73 $\mathrm{m}^{2}( \pm S D)$} \\
\hline Basal & $>90( \pm 0)$ \\
\hline At last visit & $74.2( \pm 25.1)$ \\
\hline
\end{tabular}

$\mathrm{BMI}$ - body mass index; IQR - interquartile range; eGFR - estimated glomerular filtration rate; SD standard deviation; CKD-EPI - Chronic Kidney Disease Epidemiology Collaboration patients had undergone ipsilateral $\mathrm{RNs}$, managed initially as sporadic RCC at their local institutions (mean diameter of lesions: $90 \mathrm{~mm}, \pm 0.8$ ). Patient and tumor characteristics stratified by treatment modality are summarized in Table 2.

At our department, the first treatment in every patient was decided upon specific localization of the tumor and its size. The median number of interventions per patient was three (range 1-5). Procedures for the appearance of a new solid lesion (distant from the previously treated tumoral bed or contralateral) during follow-up were required in eight patients (57\%) during a mean time (time from procedure to procedure) of $32 \pm 18.5$ months (range 16-68). Regarding interventions for a new lesion during followup, these were managed based on location, size, and previous treatment received; NSS was the most frequently performed procedure $(\mathrm{n}=5,38 \%)$, followed by RFA ( $\mathrm{n}=4,31 \%)$. Among the four patients referred to our institution with a single kidney, they required between one and 4 nephron-sparing procedures each (3 NSS, 6 RFA, and 1 SE). Pathologic tumor staging and Fuhrman's tumor grade could only be determined in patients treated with either radical nephrectomy (RN) or NSS, and all cases showed clear cell carcinoma (Table 2 ).

Failure to eradicate targeted lesions was observed in two patients, two times after RFA, and in one case after SE (success rate of FRA in our series: 85\%). Both patients received a final successful treatment with NSS.

No medical or surgical complications such as urinary tract infection, development of hematomas, wound

Table 2. Invasive procedures performed in our series of patients with von Hippel-Lindau disease associated renal cell carcinoma ( $n=13$ patients)

\begin{tabular}{|c|c|c|c|c|}
\hline & $\begin{array}{c}\text { Radical } \\
\text { nephrectomy }\end{array}$ & $\begin{array}{l}\text { Nephron-sparing } \\
\text { surgery }\end{array}$ & $\begin{array}{l}\text { Radiofrequency } \\
\text { ablation }\end{array}$ & $\begin{array}{l}\text { Selective } \\
\text { embolization }\end{array}$ \\
\hline Number of procedures, $n$ & 4 & 12 & 13 & 1 \\
\hline Number of patients*, n /total & $4 / 13$ & $10 / 13$ & $8 / 13$ & $1 / 13$ \\
\hline Mean diameter of lesions, mm ( \pm SD) & $90( \pm 0.8)$ & $31.6( \pm 8.3)$ & $2.7( \pm 8.8)$ & 26 \\
\hline Need of re-treatment for same lesion, $\mathrm{n}(\%)$ & $0(0 \%)$ & $0(0 \%)$ & $2(15 \%)$ & $1(100 \%)$ \\
\hline $\begin{array}{l}\text { pT, n (\%) } \\
\text { pT1a } \\
\text { pT1b }\end{array}$ & $\begin{array}{l}1(25 \%) \\
3(75 \%)\end{array}$ & $\begin{array}{c}11(92 \%) \\
1(8 \%)\end{array}$ & Not assessed & Not assessed \\
\hline $\begin{array}{l}\text { Fuhrman grade, n (\%) } \\
\text { I } \\
\text { II } \\
\text { III }\end{array}$ & $\begin{array}{c}2(50 \%) \\
2(50 \%) \\
0\end{array}$ & $\begin{array}{c}5(42 \%) \\
6(50 \%) \\
1(8 \%)\end{array}$ & Not assessed & Not assessed \\
\hline Transfusion rate, $\%$ & $0 \%$ & $0 \%$ & $0 \%$ & $0 \%$ \\
\hline Complications (Clavien-Dindo classification) & 0 & 0 & $\| I l b$ & 0 \\
\hline
\end{tabular}

SD - standard deviation

*Considering that patients have received more than one treatment option at a different time (except for radical nephrectomy) 
infection, nor urinary fistula were recorded, and the transfusion rate was $0 \%$. Only one high grade (IIIb) complication was reported out of 30 interventions (3\% complication rate): a colonic thermal injury during a RFA session that required a Hartmann procedure and deferred bowel reconstruction.

At the first visit, all patients presented with adequate renal function, with a mean estimated glomerular filtration rate (eGFR) of $\geq 90 \mathrm{ml} /$ minute $/ 1.73 \mathrm{~m}^{2}$ (Table 1), without associated nephropathy. Despite multiple interventions, adequate renal function was maintained in all patients at the last follow-up. Overall, mean serum creatinine at last visit was $1.0 \mathrm{mg} / \mathrm{dl}$ $( \pm 0.7)$ with a mean eGFR of $74.2 \mathrm{ml} /$ minute $/ 1.73 \mathrm{~m}^{2}$ $( \pm 25.1)$. As expected, patients with a solitary kidney developed a worse renal function outcome, of whom $50 \%$ developed stage 3 chronic kidney disease (eGFR less than $60 \mathrm{ml} /$ minute $/ 1.73 \mathrm{~m}^{2}$ ) (Table 2). No need for renal replacement therapy was observed at any time in our series.

\section{DISCUSSION}

A small proportion of RCCs are heritable (2-4\%), characterized by a younger age at presentation, and are mostly multifocal, bilateral, and recur over time [9]. At least 12 different inherited renal cancer syndromes have been described, from which VHL is the most common and widely investigated, recognized as the best-defined RCC susceptibility syndrome [2]. Approximately two-thirds of VHL patients present renal cysts and RCC, which tend to be bilateral in at least $75 \%$ of cases $[1,2,10]$. The most critical risk factor for decreased life expectancy in VHL patients is the high prevalence of RCC. The lifelong development of RCC in these patients will eventually result in chronic kidney disease after repeated surgical treatments, with the resultant higher incidence of cardiovascular events and death. Thus, the average survival in this population is around 50 years of age $[1,11,12]$.

Our series comprises 14 patients already diagnosed with VHL disease who were referred to our unit for the treatment and follow-up of small renal masses, of whom 13 received invasive treatments. The most recently updated series describing the management of kidney tumors in VHL patients range from 14 to 44 cases $[13,14,15]$.

The management of renal masses in VHL patients is considered a technical challenge. Clinical guidelines do not provide definitive recommendations for the therapeutic decisions regarding small-size RCCs because of the absence of high volume clinical trials and the absence of patients with hereditary renal cancer syndromes in the published literature
$[7,16,17]$. The decision when to excise RCCs is mainly made on the basis of the tumor size and the growth kinetics of every lesion as both of these parameters determine the risk of metastatic disease $[1,17]$. In a retrospective study described by Duffey et al. [17], tumor size was significantly associated with the likelihood of metastatic spread. In 108 reviewed patients, they used the $3 \mathrm{~cm}$ threshold to recommend surgical treatment, observing the absence of metastatic progression during a median follow-up of 41 months (range 0-244). Currently, the accepted cut-off diameter for surgical resections is considered $3 \mathrm{~cm}$ [1]. If we follow this recommendation, expected disease progression survival is achieved at a rate of $76 \%$ at 5 years and $20 \%$ at 8 years $[13,14,15,17]$. In this setting, organ-sparing strategies such as NSS should be performed whenever technically feasible, leaving RN only for cases of functional organ loss, or when the risks of preserving the remaining parenchyma outweigh the benefits.

In our series, $76 \%$ of patients underwent a NSS (12 procedures in 11 kidneys), the mean diameter of lesions was $31.6 \pm 8.3 \mathrm{~mm}$. From all $12 \mathrm{NSS}$, 8 cases were successfully performed laparoscopically, and the remaining 4 were performed using an open approach (3 patients had multiple tumors, and 1 had an ipsilateral previous laparoscopic NSS). The four patients in our series that underwent a $\mathrm{RN}$ before the referral to our center presented cT2 lesions in all cases (mean diameter of $90 \mathrm{~mm}$ ), not being suitable for a NSS.

Thirteen percutaneous ablative procedures (RFA) were performed in our cohort, all done under CT-guidance. The mean diameter of solid lesions treated by RFA was $25.7 \pm 8.8 \mathrm{~mm}$. We observed a success rate of RFA for the treatment of renal tumors of $85 \%$, with only two patients that required retreatment. In one patient, the recurrence after RFA (32 $\mathrm{mm}$ solid lesion) was treated successfully with NSS after six months of the initial procedure. The second patient, who had a solitary kidney, received a SE after six months of the FRA for a $24 \mathrm{~mm}$ lesion. This same lesion needed a new intervention, this time with a NSS 15 months after the SE (surgery was planned for the formerly described lesion and a new one of $25 \mathrm{~mm}$ ). This overall oncologic technical success rate is similar to the currently published data, with reported success rates of RFA from $90 \%$ to $100 \%$ [18-21]. During the last years, minimally invasive percutaneous techniques have gained increased relevance and have shown their efficacy in the treatment of RCC; these include CT-guided cryoablation, RFA, and MWA [8, 18, 22]. As a clinical principle, these techniques should be considered for tumors measuring $2-3 \mathrm{~cm}$ in diameter, which are not 
close to vessels or bowel structures. Tumors larger than $3 \mathrm{~cm}$ are not easily treated with RFA because of the probability of requiring multiple RFA sessions for complete ablation and the uncertainty of obtaining complete destruction of the tumor [8, 15, 21, 23]. Some technical limitations were described at the beginning of the series in patients who were not candidates for surgical resection, but later on, researchers have shown promising results of the procedures, with low complication rates [8, 23-25]. The complication rate of percutaneous ablative procedures for treating RCCs is $0-8 \%$ in patients with VHL disease [8, 21]. These include bowel perforation, ureteral strictures, uncontrolled bleeding, and residual or recurrent cancers [26]. We observed only one major complication in our series (7\%), a thermal bowel injury, which corresponds to the most frequently reported complication described in the current literature $[8,18,25]$. Bowel injury is also the most severe complication because it can eventually result in perforation, abscess formation, and sepsis [26]. The minor complication rate following ablative procedures is relatively high, reaching 58-66\%, and includes hematuria, hematomas, pneumothorax, and segmental renal infarction $[8,22]$. In the case of our patient that suffered a colon injury, bowel structures were not considered at a risky distance from the tumor, understanding that the procedure was well indicated in the first case, and the development of this complication was not expected.

Considering the high frequency of multiple neoplastic foci, and the young age at diagnosis of RCC in VHL patients, subsequent surgeries and interventions will be required in each kidney during their lifetime. The main therapeutic goal to manage RCCs in patients with VHL disease is to remove as many RCCs as possible while preserving renal function. Patients will undergo NSS for visible lesions with the general understanding that microscopic cancer cells will probably remain in non-detected foci, and will develop tumors in the future [27]. Therefore, patients and physicians should always have in mind that the number of possible interventions in one kidney may be limited, and the need for surgery should be considered carefully. The two main targets for the urologist in every patient with this disorder are to avoid metastatic disease and delay the need for dialysis. We must keep in mind that quality of life in these patients has been shown to correlate inversely with the number of operations a patient has undergone on the kidneys and central nervous system [28]. Although a gradual reduction of renal function is unavoidable following either NSS or RFA due to parenchymal loss [23, 25], recently published studies have reported that renal preservation can be achieved and not significantly reduced after percutaneous techniques for sporadic RCC [18, 22, 29, 30]. Wah et al. reported a $3.1 \%$ loss of the eGFR after RFAs when comparing the eGFR before treatment [18]. We observed a decrease of $>25 \%$ of eGFR at last visit in only one patient, which had a solitary kidney and had undergone 2 RFAs, one SE, and one partial nephrectomy, not requiring renal replacement therapy at last follow-up.

After successful treatments, we observed the appearance of new lesions (distant to the operated kidney surgical bed) requiring active treatment in 8 patients (57\%) within a mean time of $32 \pm 18.5$ months (range 16-68). In a relevant published series by Ploussard et al. [13], in 21 VHL patients with RCC, 8 (38\%) developed new lesions, at a median time of 43 months (range 10-115). Our shorter time to disease progression can be explained by the use of percutaneous ablative techniques (RFA) to treat smaller renal lesions in our patients. If we only take into account patients who underwent a repeated NSS for a new renal lesion (5 cases, 36\%), like Ploussard et al., the median time to progression was similar: 41 months (range 5-64) [13].

In the present series, we outline that all patients referred to our center, whether their status was treatment naïve or with a solitary kidney after an initial $\mathrm{RN}$, were treated successfully according to our internal protocol. We managed to preserve renal function in all cases, and no development of metastases or death was documented during follow-up.

\section{CONCLUSIONS}

VHL is a rare hereditary disease that can develop bilateral synchronous and metachronous RCCs. Management of VHL kidney disease by NSS is the standard of care with a cut-off at $3 \mathrm{~cm}$, while ablative procedures should be offered to lesions ranging 2-3 cm in size distant from vessels or bowel structures. Minimally invasive procedures like NSS or percutaneous RFA offer good oncologic results with an acceptable complication rate. Patients should be closely followed up and managed in referral centers, which can offer all treatment options to preserve renal function and control oncologic progression.

\section{CONFLICTS OF INTEREST}

The authors declare no conflicts of interest.

\section{FUNDING}

This research was funded by Madrid Regional Government Research Grant [S2010/BMD-2326 IMMUNOTHERCAN-CM (B2017/ BMD-3733)/FEDER]. 


\section{References}

1. Bausch B, Jilg C, Gläsker S, et al. Renal cancer in von Hippel-Lindau disease and related syndromes. Nat Rev Nephrol. 2013; 9: 529-538.

2. Lonser RR, Glenn GM, Walther M, et al. von Hippel-Lindau disease. Lancet. 2003; 361: 2059-2067.

3. Maher ER, Neumann HP, Richard S. von Hippel-Lindau disease: a clinical and scientific review. Eur J Hum Genet. 2011; 19: 617-623.

4. Richard S, Graff J, Lindau J, et al. Von Hippel-Lindau disease. Lancet. 2004; 363: 1231-1234.

5. Meister M, Choyke P, Anderson C, Patel U. Radiological evaluation, management, and surveillance of renal masses in Von Hippel-Lindau disease. Clin Radiol. 2009; 64: 589-600.

6. Guðmundsson E, Hellborg H, Lundstam S, Erikson S, Ljungberg B; Swedish Kidney Cancer Quality Register Group. Metastatic potential in renal cell carcinomas $\leq 7 \mathrm{~cm}$ : Swedish Kidney Cancer Quality Register data. Eur Urol. 2011; 60: 975-982.

7. Ljungberg $B$, Albiges $L$, Abu-Ghanem $Y$, et al. European Association of Urology Guidelines on Renal Cell Carcinoma: The 2019 Update. Eur Urol. 2019; 75: 799-810.

8. Park BK, Kim CK, Park SY, Shen SH. Percutaneous radiofrequency ablation of renal cell carcinomas in patients with von Hippel Lindau disease: indications, techniques, complications, and outcomes. Acta Radiol. 2013; 54: 418-427.

9. Linehan $\mathrm{Wm}$, Walther $\mathrm{Mm}$, Zbar B. The Genetic Basis of Cancer of the Kidney. J Urol. 2003; 170: 2163-2172.

10. Malek RS, Omess PJ, Benson RC Jr, Zincke $H$. Renal cell carcinoma in von Hippel-Lindau syndrome. Am J Med. 1987; 82: 236-238.

11. Wilding A, Ingham SL, Lalloo F, et al. Life expectancy in hereditary cancer predisposing diseases: an observational study. J Med Genet. 2012; 49: 264-269.
12. Maddock IR, Moran A, Maher ER, et al. A genetic register for von Hippel-Lindau disease. J Med Genet. 1996; 33: 120-127.

13. Ploussard G, Droupy S, Ferlicot S, et al. Local Recurrence After Nephron-Sparing Surgery in von Hippel-Lindau Disease. Urology. 2007; 70: 435-439.

14. Matin SF, Ahrar K, Wood CG, Daniels M, Jonasch $E$. Patterns of intervention for renal lesions in von Hippel-Lindau disease. BJU Int. 2008; 102: 940-945.

15. Herring JC, Enquist EG, Chernoff A, Linehan WM, Choyke PL, Walther MM. Parenchymal sparing surgery in patients with hereditary renal cell carcinoma: 10-year experience. J Urol. 2001; 165: 777-781.

16. Smaldone MC, Kutikov A, Egleston BL, et al. Small renal masses progressing to metastases under active surveillance: a systematic review and pooled analysis. Cancer. 2012; 118: 997-1006.

17. Duffey Bg, Choyke PI, Glenn G, et al. The relationship between renal tumor size and metastases in patients with von HippelLindau disease. J Urol. 2004; 172: 63-65.

18. Wah TM, Irving HC, Gregory W, Cartledge J, Joyce AD, Selby PJ. Radiofrequency ablation (RFA) of renal cell carcinoma (RCC): Experience in 200 tumours. BJU Int. 2014 ; 113: 416-428.

19. Breen DJ, Rutherford EE, Stedman B, et al. Management of renal tumors by image-guided radiofrequency ablation: experience in 105 tumors. Cardiovasc Intervent Radiol. 2007; 30: 936-942.

20. Zagoria RJ, Pettus JA, Rogers M, Werle DM, Childs D, Leyendecker JR. Longterm outcomes after percutaneous radiofrequency ablation for renal cell carcinoma. Urology. 2011; 77: 1393-1397.

21. Gervais DA, McGovern FJ, Arellano RS, McDougal WS, Mueller PR. Radiofrequency ablation of renal cell carcinoma: part 1 , Indications, results, and role in patient management over a 6-year period and ablation of 100 tumors. AJR Am J Roentgenol. 2005; 185: 64-71.
22. Yang B, Autorino R, Remer EM, et al. Probe ablation as salvage therapy for renal tumors in von Hippel-Lindau patients: the Cleveland Clinic experience with 3 years follow-up. Urol Oncol. 2013; 31: 686-692.

23. Park SY, Park BK, Kim CK, et al. Percutaneous radiofrequency ablation of renal cell carcinomas in patients with von Hippel Lindau disease previously undergoing a radical nephrectomy or repeated nephronsparing surgery. Acta Radiol. 2011; 52: 680-685.

24. Iwamoto Y, Kanda H, Yamakado K, et al. Management of renal tumors in Von Hippel-Lindau disease by percutaneous CT fluoroscopic guided radiofrequency ablation: preliminary results. Fam Cancer. 2011; 10: 529-534.

25. Park BK, Kim CK. Percutaneous radio frequency ablation of renal tumors in patients with von Hippel-Lindau disease: preliminary results. J Urol. 2010; 183: 1703-1707.

26. Park BK, Kim CK. Complications of imageguided radiofrequency ablation of renal cell carcinoma: causes, imaging features and prevention methods. Eur Radiol. 2009; 19: 2180-2190.

27. Reed AB, Parekh DJ. Surgical management of von Hippel-Lindau disease: urologic considerations. Surg Oncol Clin N Am. 2009; 18: 157-174.

28. Shuin T, Yamasaki I, Tamura K, Okuda H, Furihata M, Ashida S. Von Hippel-Lindau disease: molecular pathological basis, clinical criteria, genetic testing, clinical features of tumors and treatment. Jpn J Clin Oncol. 2006; 36: 337-343.

29. Pettus JA, Werle DM, Saunders W, et al. Percutaneous radiofrequency ablation does not affect glomerular filtration rate. J Endourol. 2010; 24: 1687-1691.

30. Weisbrod AJ, Atwell TD, Frank I, et al. Percutaneous cryoablation of masses in a solitary kidney. AJR Am J Roentgenol. 2010; 194: 1620-1625. 